\title{
Fertility of rats with artificial oligozoospermia
}

\author{
J. H. Aafjes*, J. M. Vels and E. Schenck \\ Department of Endocrinology, Growth and Reproduction, Faculty of Medicine, \\ Erasmus University, Rotterdam, The Netherlands
}

\begin{abstract}
Summary. Three different methods to obtain "oligospermic" rats were investigated. (1) Surgical reduction of the amount of tubular tissue diminished the number of spermatozoa present in the epididymis, but the animals were not infertile as long as they were able to ejaculate ( $32 / 33$ rats). (2) Treatment with oestradiol benzoate on the 5th day after birth caused only slight reduction of spermatogenesis and most of these animals were fertile. (3) X-irradiation of 20 male rats 1-3 days before birth yielded 8 rats with severely diminished spermatogenesis which were infertile although they did mate and spermatozoa were observed in vaginal smears. This suggests that 'spotty' spermatogenesis in the testes of these animals (as in infertile men) results in spermatozoa of diminished fertility.
\end{abstract}

\section{Introduction}

From a group of 354 men investigated for unwanted childlessness $53.1 \%$ were oligozoospermic (Aafjes \& van der Vijver, 1976). In only a minority of these men could a "cause" for their oligospermia, like cryptorchidism, varicocoele or infection, be detected. What defines which of these patients will eventually impregnate his partner cannot be predicted. The more so because in men with oligozoospermia the spermatozoa are not only low in number but commonly also show abnormal morphology and/or low motility (Freund, 1962). However, it has been shown that a high score for a testicular biopsy rating could be related to the chance of fertilization (Aafjes, van der Vijver, Docter \& Schenck, 1977; Aafjes, van der Vijver, \& Schenck, 1978a). These authors use a scoring method originally described by Johnsen (1970) and somewhat modified by Aafjes \& van der Vijver (1974) to classify spermatogenesis of oligospermic men. At least 100 tubular cross-sections are given score numbers from 1 to 10 depending on the most advanced stage of spermatogenesis present. Complete spermatogenesis with more than 5 spermatozoa per cross-section is rated as 10 . The modification introduced is that score 9 , defined by Johnsen (1970) as disorganized epithelium with marked sloughing or obliteration of lumen, is omitted. Patients with a low mean biopsy score as a result of several tubular cross-sections with severely defective or absent spermatogenesis in their testis tissue (spotty spermatogenesis) were found to have a low chance of fertility. Patients with higher mean scores as a result of a more even distribution of slightly diminished spermatogenesis were significantly more often fertile, although the degree of oligospermia, as judged by sperm count, motility and morphology, was comparable. The hormonal data of these patients with different biopsy scores were also similar (Aafjes et al., 1977). Cause and effects of oligozoospermia are thus poorly understood. For a better understanding of this 'disease' an animal model might be helpful. To this purpose spermatogenesis in rats was reduced in three different ways, and the results of these treatments are reported.

\section{Materials and Methods}

Hybrid Wistar rats bred in our laboratory were used. They were kept under controlled light $(06: 00-18: 00 \mathrm{~h})$ and temperature $\left(20-23^{\circ} \mathrm{C}\right)$ conditions. Spermatogenesis in the rats was reduced in three different ways: (1) surgical reduction of the spermatogenic epithelium; (2)

* Present address: University of Suriname (M.W.I.), P.O. Box 537, Paramaribo, Suriname. 
oestrogen treatment after birth, which may lead to delayed puberty and diminished fertility as shown by Brown-Grant, Fink, Greig \& Murray (1975); and (3) prenatal X-irradiation 1-3 days before birth (Beaumont, 1960).

\section{Surgical reduction of the spermatogenic epithelium}

Rats at 3 months of age were anaesthetized with ether and one of the testes was made smaller by removing with fine forceps some of the tubular tissue (200-600 mg) through a small incision in the testicular capsule. Care was taken to avoid damaging the vessels. If haemorrhage did occur the animal was discarded. The incision in the capsule was closed with one fine silk suture and then the other testis and epididymis were removed after ligation of the vessels. At 5 weeks after the operation the animals were tested for fertility. This period of 5 weeks is sufficient to deplete the epididymis of fertile spermatozoa produced before the operation (Vreeburg, Bielska \& Ooms, 1976).

\section{Oestrogen administration}

At 5 days after birth male rats were injected subcutaneously with 30 or $100 \mu \mathrm{g}$ oestradiol benzoate (Organon Oss) in $0.05 \mathrm{ml}$ arachis oil. When these animals were 8 months old they were separately caged with two females to test their fertility and at 12 months of age they were killed.

\section{$X$-irradiation}

Pregnant rats were irradiated 1-3 days before parturition with a Philips-Müller M.G. 300 Xray machine. Physical constants were: $250 \mathrm{kV} ; 10 \mathrm{~mA}$ : added filtration $1.0 \mathrm{~mm} \mathrm{Cu}$; focus object distance $53 \mathrm{~cm}$; dose rate $30-35 \mathrm{rad} / \mathrm{min}$. During irradiation the dose was measured with a Baldwin Ionex dosimeter. The total dose was 135 rad per rat. Six rats born 1 day after Xirradiation and 6 rats born 2 days after $X$-irradiation were tested for fertility at 3-6 months of age and then killed. Eight other rats born 2-3 days after $\mathrm{X}$-irradiation were tested for fertility at 4-12 months and then killed.

\section{Counting of spermatozoa in the epididymides}

After autopsy the epididymides were dissected free from the testes. Fat tissue was carefully removed and then each epididymis was divided into a head and a tail part by cutting through the middle of the corpus. After weighing, the head and tail parts were separately ground in $10 \mathrm{ml}$ physiological saline $(0.9 \%(\mathrm{w} / \mathrm{v}) \mathrm{NaCl})$ with an ultra-turrax (Janke \& Künkel, Staufen; about $7000 \mathrm{rev} / \mathrm{min}$ for $2.2 \mathrm{~min}$ ). Counts of sperm heads in these homogenates were obtained with a haemocytometer counting chamber.

\section{Testing for fertility}

Experimental males were separately caged with 2 intact females for at least 1 month to test their fertility. The number of nests and young were noted. Males who did not fertilize were further tested by caging them for 1 night with a receptive female. These females were either intact females on the day of pro-oestrus or spayed females made receptive by s.c. injection of $100 \mu \mathrm{g}$ oestradiol benzoate (Organon Oss) in $0.1 \mathrm{ml}$ oil and $2 \mathrm{mg}$ progesterone (Organon Oss) in $0.1 \mathrm{ml}$ oil $48 \mathrm{~h}$ later at 18:00 $\mathrm{h}$ on the day before testing. The next morning vaginal smears were obtained to observe whether the animals had copulated and whether spermatozoa were present. 


\section{Hormone determinations}

Blood samples were taken at autopsy and used for measurement of serum LH, FSH and testosterone. $\mathrm{LH}$ and $\mathrm{FSH}$ were determined with double-antibody radioimmunoassays, using antisera obtained from rabbits immunized with ovine LH and FSH preparations (Welschen et al., 1975). The standards were NIAMDD-rat-LH and -FSH RP1 preparations. The coefficients of variation for LH and FSH determinations in serum pools were $10-15 \%$. The sensitivities of the assays were estimated at $2.65 \pm 0.34 \mathrm{ng} \mathrm{LH}-\mathrm{RP} 1$ and $6.8 \pm 0.9 \mathrm{ng}$ FSH RP1 (depression to $90 \%$ binding). Testosterone was determined by radioimmunoassay as described by Verjans, Cooke, de Jong, de Jong \& van der Molen (1973). The procedure involves addition of $\left[{ }^{3} \mathrm{H}\right]-$ testosterone as an internal standard and chromatography of serum extracts on alumina columns. This column chromatography step removes $97 \% 5 \alpha$-dihydrotestosterone. The recovery of added $\left[{ }^{3} \mathrm{H}\right]$ testosterone was $60-70 \%$. Reproducibility of plasma assays was between 10 and $15 \%$. The sensitivity was $0.1 \mathrm{ng}$ testosterone $/ \mathrm{ml}$.

\section{Statistical analysis}

Statistical analyses were carried out by using Student's $t$ test. The correlation measure used was the product moment correlation coefficient.

\section{Results}

For comparison with the experimental animals, some results obtained from 6 control males caged together and from 6 males caged individually with a receptive female for 1 night and autopsied the next morning are given in Table 1. From the table it can be seen that the number of spermatozoa in the epididymides of rats which stayed for 1 night with a receptive female was about $100 \times 10^{6}$ lower than the number present in the epididymides of rats caged with other males. This was accompanied by a significant diminution of the epididymal weight. In contrast the seminal vesicle and prostate weights were not different.

Table 1. Mean \pm s.e.m. values for body weight, organ weights and number of epididymal spermatozoa for 6 male rats caged together and 6 males which had been caged with a receptive female during the night before autopsy

\begin{tabular}{|c|c|c|}
\hline & Rats caged together & $\begin{array}{l}\text { Rats caged with a } \\
\text { receptive female }\end{array}$ \\
\hline Body weight (g) & $401 \cdot 3 \pm 9 \cdot 5$ & $410 \cdot 0 \pm 11.0$ \\
\hline Testis wt (mg) & $1503 \cdot 5 \pm 13 \cdot 7$ & $1430 \cdot 5 \pm 15 \cdot 5^{*}$ \\
\hline Wt of paired seminal vesicles (mg) & $320 \cdot 0 \pm 7 \cdot 3$ & $317 \cdot 6 \pm 13 \cdot 2$ \\
\hline Wt of ventral prostate $(\mathrm{mg})$ & $382 \cdot 5 \pm 14 \cdot 4$ & $395.6 \pm 13.8$ \\
\hline \multicolumn{3}{|l|}{ Wt of epididymis } \\
\hline Total (mg) & $615.1 \pm 8.8$ & $529 \cdot 6 \pm 16 \cdot 7^{* *}$ \\
\hline Head (mg) & $301.5 \pm 3.5$ & $277.9 \pm 8.3$ \\
\hline Tail (mg) & $314.0 \pm 8.2$ & $246 \cdot 7 \pm 9 \cdot 7^{* *}$ \\
\hline \multicolumn{3}{|l|}{ No. of epididymal spermatozoa } \\
\hline Total $\times 10^{6}$ & $236.8 \pm 4.7$ & $131 \cdot 0 \pm 4 \cdot 2^{* *}$ \\
\hline In head $\times 10^{6}$ & $72.0 \pm 2.9$ & $60.8 \pm 3.1$ \\
\hline In tail $\times 10^{6}$ & $164.9 \pm 3.0$ & $70 \cdot 3 \pm 3 \cdot 3^{* *}$ \\
\hline
\end{tabular}

All the animals were 6 months old at autopsy. The data from paired organs are means except for the seminal vesicles.

$* P<0.05 ;{ }^{* *} P<0.01$ compared with values in the rats caged together. 
Table 2. Mean \pm s.e.m. values for body weight, organ weights and hormonal data from 34 rats with one reduced testis

\begin{tabular}{|c|c|c|}
\hline & $\begin{array}{l}\text { Rats with epididymal } \\
\text { spermatozoa }(\mathrm{N}=25)\end{array}$ & $\begin{array}{l}\text { Rats without epididymal } \\
\text { spermatozoa }(\mathrm{N}=9)\end{array}$ \\
\hline $\begin{array}{l}\text { Body weight (g) } \\
\text { Testis weight (mg) }\end{array}$ & $\begin{array}{l}422.8 \pm 6.8 \\
574.9 \pm 32.4\end{array}$ & $\begin{array}{l}434.4 \pm 8 \cdot 8 \\
324.1+22.6^{* *}\end{array}$ \\
\hline Wt of paired seminal vesicles (mg) & $313.3 \pm 8 \cdot 5$ & $\begin{array}{l}324.1 \pm 22.6 \\
284.6 \pm 19.4\end{array}$ \\
\hline Wt of ventral prostate $(\mathrm{mg})$ & $287.4 \pm 10.7$ & $267.1 \pm 28.2$ \\
\hline Wt of epididymis (mg) & $332.9 \pm 11.6$ & $289.6 \pm 36.8$ \\
\hline LH conc. $(\mathrm{ng} / \mathrm{ml})$ & $133 \cdot 0 \pm 16 \cdot 3$ & $232 \cdot 6 \pm 50 \cdot 6^{*}$ \\
\hline FSH conc. $(\mathrm{ng} / \mathrm{ml})$ & $809 \cdot 6 \pm 46 \cdot 6$ & $1204.6 \pm 171.9^{* *}$ \\
\hline Testosterone conc. $(\mathrm{ng} / \mathrm{ml}) \dagger$ & $1.9 \pm 0.2(16)$ & $1.6 \pm \quad 0.2(8)$ \\
\hline
\end{tabular}

The rats were 6 months old at autopsy.

* $P<0.05 ;{ }^{* *} P<0.01$ compared with values for rats with epididymal spermatozoa.

$\dagger$ For the no. of samples indicated in parentheses.

\section{Rats with one reduced testis}

In Table 2 some of the results obtained from 34 rats with one reduced testis are given. Rats which did not have epididymal spermatozoa had a significantly smaller testis and higher FSH and $\mathrm{LH}$ values than animals which did have epididymal spermatozoa. The 34 animals in Table 2 and 11 others with one small testis from which no hormonal data were obtained were tested for fertility. A significant correlation $(r=0.95 ; P<0.01)$ existed between testicular weight and number of spermatozoa present in the epididymis (Text-fig. 1). Of the 34 animals with epididymal spermatozoa, 32 were fertile, even when the number of spermatozoa in the epididymis was of the order of $1 \times 10^{6}$. One of the two animals which did not fertilize had a total of $1 \times 10^{6}$ epididymal spermatozoa but there were no spermatozoa in the vaginal smears after tests with 3 different receptive females. However, in the same test, the other infertile male showed repeatedly positive smears. Histological preparations of the testis of this animal showed what we

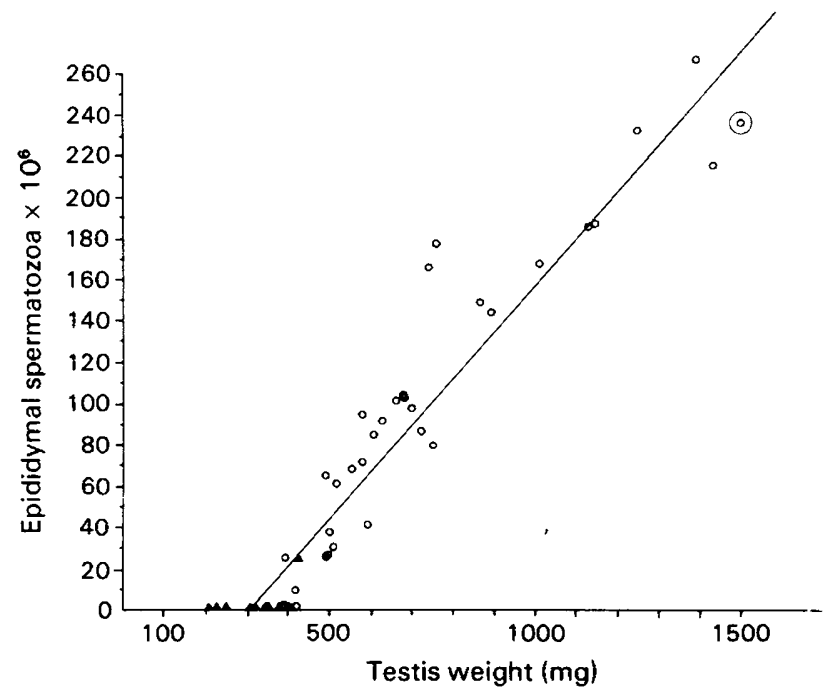

Text-fig. 1. Relationship between testicular weight and number of spermatozoa in the epididymis of hemicastrated rats in which the remaining testis was made smaller by removing $200-600 \mathrm{mg}$ of tubular tissue. The regression equation is $y=0 \cdot 23 x-69 \cdot 3$. $\odot$, Data obtained from 6 intact males (Table 1); $\Lambda$, infertile males; $O$, fertile males. 
suppose to be an area of extra-tubular spermatogenesis (Pl. 1, Fig. 1). In these preparations this was seen in two interconnected areas, which extended over about 180 sections of $10 \mu \mathrm{m}$ thickness. Histological preparations of testis from the other animals with reduced testes never showed such a picture. Spermatogenesis was present in only a few tubules; most of the tubules contained only Sertoli cells and some were filled with debris of sperm cells (Pl. 1, Fig. 2).

\section{Oestrogen-treated males}

Compared with results obtained from the normal males (Table 1), the epididymal, prostate and seminal vesicle weights were lower in the oestradiol benzoate-treated males (Table 3) although these animals were 6 months older. The number of spermatozoa was also reduced but fertility tests showed that 16 out of 19 animals fertilized at least 1 female when caged with 2 female rats during a period of 4 months. Two of the animals treated with $30 \mu \mathrm{g}$ oestradiol benzoate and 1 of those treated with $100 \mu \mathrm{g}$ did not fertilize although tests with receptive females showed that they had mated and could ejaculate spermatozoa. Testicular histology of oestradiol benzoate-treated males showed spermatogenesis in all tubules.

Table 3. Mean \pm s.e.m. values for body weight, organ weights, number of epididymal spermatozoa and hormonal data for 19 rats treated with oestradiol benzoate on Day 5 after birth and 20 rats treated with 135 rad X-rays before birth

\begin{tabular}{|c|c|c|c|c|c|}
\hline & \multicolumn{2}{|c|}{ Oestradiol benzoate } & \multicolumn{3}{|c|}{$\mathrm{X}$-irradiation } \\
\hline & $30 \mu \mathrm{g}$ & $100 \mu \mathrm{g}$ & 1 day & 2 days & $2-3$ days \\
\hline Number of rats & $12 \ddagger$ & $7 \ddagger$ & $6 \dagger$ & $6 \dagger$ & $8 \ddagger$ \\
\hline Body weight (g) & $413 \cdot 3 \pm 8 \cdot 9$ & $357 \cdot 1 \pm 5 \cdot 6^{* *}$ & $320.0 \pm 5.8$ & $350.0 \pm 7.3$ & $395.0 \pm 7.6$ \\
\hline Testis wt (mg) & $1466 \cdot 5 \pm 45 \cdot 1$ & $1335 \cdot 0 \pm 25 \cdot 8^{*}$ & $480.7 \pm 132.0$ & $326 \cdot 7 \pm 22 \cdot 5$ & $241 \cdot 0 \pm 14 \cdot 7$ \\
\hline $\begin{array}{l}\text { Wt of paired seminal } \\
\text { vesicles (mg) }\end{array}$ & $174 \cdot 0 \pm 10 \cdot 4$ & $154.9 \pm 8.0$ & $299.2 \pm 43 \cdot 0$ & $300 \cdot 2 \pm 28 \cdot 6$ & $189.3 \pm 9.1$ \\
\hline Wt of ventral prostate $(\mathrm{mg})$ & $170 \cdot 0 \pm 17 \cdot 0$ & $138.2 \pm 8.5$ & $312.3 \pm 52.1$ & $353.0 \pm 24.7$ & $233.7 \pm 12.9$ \\
\hline \multicolumn{6}{|l|}{ Wt of epididymis } \\
\hline Total $(\mathrm{mg})$ & $435 \cdot 6 \pm 24 \cdot 7$ & $361 \cdot 7 \pm 13 \cdot 5^{*}$ & $219.3 \pm 32.8$ & $186 \cdot 5 \pm 11 \cdot 1$ & $153.7 \pm 11.8$ \\
\hline Head (mg) & $195.4 \pm 12.2$ & $152.8 \pm 4.8^{*}$ & $106 \cdot 2 \pm 16 \cdot 8$ & $101.9 \pm 8.9$ & $74.8 \pm 8.0$ \\
\hline Tail (mg) & $240 \cdot 3 \pm 14 \cdot 1$ & $208.8 \pm 11.4$ & $113 \cdot 2 \pm 16 \cdot 2$ & $84.6 \pm 2.9$ & $78 \cdot 8 \pm 4.4$ \\
\hline \multicolumn{6}{|l|}{$\begin{array}{l}\text { No. of epididymal } \\
\text { spermatozoa }\end{array}$} \\
\hline Total $\times 10^{6}$ & $174 \cdot 7 \pm 16 \cdot 0$ & $146 \cdot 0 \pm 13 \cdot 0$ & $32.4 \pm 16.4$ & $7.6 \pm 3.6$ & $4 \cdot 2 \pm 3 \cdot 4$ \\
\hline In head $\times 10^{6}$ & $51 \cdot 1 \pm 5.0$ & $42.5 \pm 3.0$ & $11 \cdot 2 \pm 5.0$ & $3 \cdot 6 \pm 2 \cdot 2$ & $1.2 \pm 1.0$ \\
\hline In tail $\times 10^{6}$ & $123.6 \pm 11.9$ & $103.5 \pm 10.8$ & $21.3 \pm 11.4$ & $4.0 \pm 2.0$ & $3.0 \pm 2.5$ \\
\hline LH conc. $(\mathrm{ng} / \mathrm{ml})$ & $<20$ & $<20$ & $48 \cdot 8 \pm 11 \cdot 3$ & $73.2 \pm 17.2$ & $104.8 \pm 14.5$ \\
\hline FSH conc. (ng/ml) & $252 \cdot 2 \pm 11 \cdot 2$ & $263.8 \pm 19.5$ & $628.5 \pm 40.7$ & $639.2 \pm 83.0$ & $665 \cdot 1 \pm 65 \cdot 5$ \\
\hline Testosterone conc. (ng/ml) & $1.3 \pm 0.2$ & $2.6 \pm 1.4$ & $2.6 \pm 0.4$ & $3.3 \pm 0.5$ & $1.4 \pm 0.1$ \\
\hline
\end{tabular}

* $P<0.05 ;{ }^{* *} P<0.01$ compared with values for rats treated with $30 \mu \mathrm{g}$ oestradiol benzoate.

+6 months of age.

$\ddagger 12$ months of age.

\section{$X$-irradiated males}

Organ weights, epididymal sperm counts and hormonal data of these animals are given in Table 3. Except for the body weight $(P<0.01)$ there were no significant differences between rats irradiated 1 or 2 days before birth. The third group of animals was tested for fertility for a longer period of time to observe whether any improvement in spermatogenesis would develop. From 4 to 8 months of age they were caged with 2 cyclic females and thereafter they were tested with receptive cyclic females on at least 3 occasions, before being killed at 12 months (Table 3 ). The 
Table 4. Fertility of 20 male rats $\mathrm{X}$-irradiated with $135 \mathrm{rad} 1-3$ days before birth

\begin{tabular}{llll}
\hline & \multicolumn{3}{l}{ Time of irradiation (days) } \\
\cline { 2 - 4 } & 1 & 2 & $2-3$ \\
\hline No. of animals & 6 & 6 & 8 \\
Fertile & 3 & 1 & - \\
Infertile but spermatozoa in vaginal smear & 1 & 2 & 5 \\
Infertile and no spermatozoa in vaginal smear & 1 & 2 & 2 \\
Infertile and no epididymal spermatozoa & 1 & 1 & 1 \\
\hline
\end{tabular}

fertility of the $\mathrm{X}$-irradiated rats and results of vaginal smear tests are given in Table 4 . It shows that 8 of these animals were infertile although spermatozoa were ejaculated. Testicular histology of the irradiated animals was very similar to that of the animals with one reduced testis. There were many atrophic tubules with Sertoli cells only and sporadic tubules containing spermatogenesis. Tubules filled with debris of spermatozoa were not observed (Pl. 1, Fig. 3).

\section{Discussion}

Comparison of the results obtained from irradiated rats with those obtained from animals with one small testis shows an interesting difference. With both techniques severe oligospermia and azoospermia, as judged by epididymal sperm counts, could be obtained. All the rats with one small testis which mated were fertile when they had epididymal spermatozoa except for the one animal with extra-tubular spermatogenesis. Why this particular animal was infertile is not clear; the abnormal spermatogenesis was presumably related to the tubule removal technique. In the other animals it may be supposed that their spermatozoa were produced in small pieces of normal tubule still attached to the rete testis and unaffected by the surgical procedure. In the testes of the irradiated rats, however, spermatogenesis appeared to be localized in small pieces of tubules distributed throughout the testis, not necessarily continuous with the rete testis. This probably caused infertility in a number of rats although these animals did mate and produce some spermatozoa. It is thought unlikely that the irradiation as such was responsible for this infertility because four of these animals were fertile. Irradiation of the animals was therefore a successful method for inducing 'spotty' spermatogenesis because these rats produced spermatozoa but were not always able to fertilize. In contrast, spermatozoa produced in stretches of normal tubules connected to the rete testis are fertile, even when produced in extremely low numbers, as by the animals with a reduced testis.

These findings are considered to support a hypothesis put forward by Aafjes et al. (1978a) on the relation between testicular histology and fertility of oligozoospermic men (see 'Introduction'), i.e. that spotty spermatogenesis "negatively influence(d) the normal ripening or transport processes or both in the tubules, resulting in defective spermatozoa with low fertilizing capacity".

\section{PLATE 1}

Fig. 1. 'Extra-tubular' spermatogenesis in a hemicastrated rat from which the remaining testis was made smaller by removing $500 \mathrm{mg}$ tubular tissue 3 months before autopsy. $\times 1510$.

Fig. 2. The remaining testis of a hemicastrated rat. From this testis $450 \mathrm{mg}$ tubular tissue was removed 3 months before autopsy. This animal was fertile and sired 4 litters of 38 young. $\times 44$.

Fig. 3. The testis of a rat irradiated with $350 \mathrm{rad} 1$ day before birth. This animal was fertile and sired 3 litters of 18 young. The variation in occurrence of spermatogenesis is clearly seen. $\times 44$. 
PLATE 1
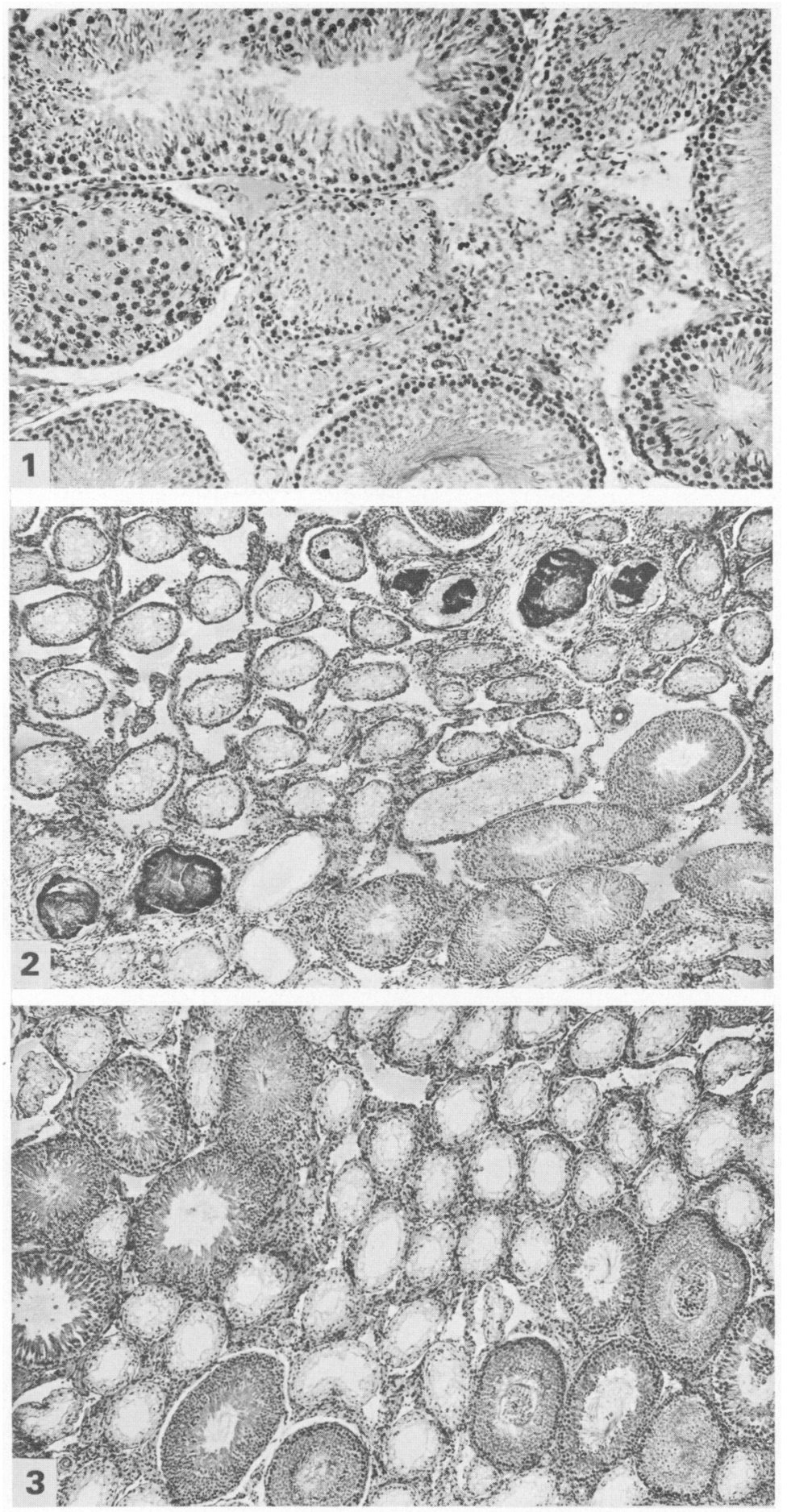

(Facing p. 350) 
FSH values of male rats in our colony are about $400-500 \mathrm{ng}$ NIH-rat-RP1/ml and LH values $50-70 \mathrm{ng}$ NIH-rat-RP1/ml (Aafjes et al., 1978b). The rats with irradiated testes appeared to have slightly elevated serum FSH levels compared with normal rats. For the rats with one small testis FSH levels were even higher and LH was also increased, but most of the animals were still fertile. Lower FSH and $\mathrm{LH}$ values than in normal rats were seen in the rats injected with oestradiol benzoate 5 days after birth, but spermatogenesis was 'normal' in the sense that most of these animals were fertile.

It is concluded that rats irradiated shortly before birth are most suitable to investigate infertility 'caused' by oligospermia.

We thank Dr F. F. G. Rommerts for the irradiated rats.

\section{References}

Aafjes, J.H. \& van der Vijver, J.C.M. (1974) A relationship between biopsy score count and fertility of men treated for oligospermia. Fert. Steril. 25, 809-812.

Aafjes, J.H. \& van der Vijver, J.C.M. (1976) 354 mannen met verminderde vruchtbaarheid. Ned. $T$. Geneesk. 120, 865-873.

Aafjes, J.H., van der Vijver, J.C.M., Docter, R. \& Schenck, P.E. (1977) Serum gonadotrophins testosterone and spermatogenesis in sub-fertile men. Acta endocr., Copenh. 86, 651-658.

Aafjes, J.H., van der Vijver, J.C.M. \& Schenck, P.E. (1978a) Value of a testicular biopsy rating for prognosis in oligozoospermia. Br. med. J. 1, 289293.

Aafjes, J.H., Vreeburg, J.T.M. \& Schenck, P.E. (1978b) Serum gonadotropins in rats after castration or heat treatment of the testis. Acta endocr., Copenh. 88, 260-273.

Beaumont, H.M. (1960) Changes in the radio sensitivity of the testis during foetal development. Int. J. Rad. Biol. 2, 247-256.

Brown-Grant, K., Fink, G., Greig, F. \& Murray, M.A.F. (1975) Altered sexual development in male rats after oestrogen administration during the neonatal period. J. Reprod. Fert. 44, 25-42.

Freund, M. (1962) Interrelationships among the characteristics of human semen and factors affecting semen-specimen quality. J. Reprod. Fert. 4, 143-159.

Johnsen, S.G. (1970) Testicular biopsy score count-a method for registration of spermatogenesis in human testes: normal values and results in 335 hypogonadal males. Hormones 1, 1-24.

Verjans, H.L., Cooke, B.A., de Jong, F.H., de Jong, C.M.M. \& van der Molen, H.J. (1973) Evaluation of a radioimmunoassay for testosterone estimation. $J$. Steroid Biochem. 4, 665-676.

Vreeburg, J.T.M., Bielska, M. \& Ooms, M. (1976) Maturation and survival of spermatozoa in the epididymis of pregnenolone treated hypophysectomized rats. Endocrinology 99, 824-830.

Welschen, R., Osman, P., Dullaart, J., de Greef, W.J., Uilenbroek, J.Th.J. \& de Jong, F.H. (1975) Levels of follicle-stimulating hormone, luteinizing hormone, oestradiol-17 $\beta$ and progesterone, and follicular growth in the pseudopregnant rat. J. Endocr. 64, 3747.

Received 10 May 1979 